“Transfer” XV: 1-2 (2020), pp. 434-450. ISSN: 1886-554

\title{
ROMPER LA SEGUNDA FRONTERA. HELGA SCHNEIDER Y ORNELA VORPSI: PIONERAS DE LA LITERATURA ITALIANA DE LA INMIGRACIÓN TRADUCIDA AL ESPAÑOL
}

Sara Velázquez García (ORCID: 0000-0003-3274-3629) Universidad de Salamanca

\section{Traducciones y literatura de la inmigración}

Los radicales cambios comenzados a finales del siglo XX y consolidados en el presente siglo XXI han asentado los cimientos de una nueva interconexión planetaria que ha venido a confirmar los augurios de una aldea global. La información viaja entre los rincones más alejados del planeta a una velocidad nunca vista hasta ahora y, en gran medida, el intercambio cultural también. La internacionalización tiene que ver con una aspiración del mercado empresarial, pero también con la repercusión de creadores de todos los ámbitos. También en el mundo editorial tiene sus implicaciones. Las traducciones se han convertido en uno de los apartados esenciales de las ventas de libros en la mayoría de países europeos.

En Francia, las traducciones rondan el 18\% de la oferta editorial; y en Alemania rondan el 13\%. En el caso de España, aunque el número varía acorde a los vaivenes del propio sector, los libros traducidos representan ya más del $20 \%$ del mercado de libros nuevos, alcanzando en 2018 los 14000 títulos.

No obstante, no se trata de un fenómeno homogéneo que haya abierto las puertas de la traducción a todos los sectores por igual. En España, se sigue traduciendo fundamentalmente del inglés (6524 títulos en 2018), pero el italiano ha comenzado a cobrar un peso específico muy relevante (594 títulos en 2018), destacando, sin duda, el empuje de una generación de escritores de novela negra que han tenido una gran acogida por parte del público español (Camilleri, Manzini, Vichi, Dazieri, Zilahy, Carlotto, 
“Transfer” XV: 1-2 (2020), pp. 434-450. ISSN: 1886-554

De Giovanni, Tuti, por citar algunos) y también a fenómenos mundiales como Paolo Giordano o Elena Ferrante.

Pero fuera de estos dos ámbitos, otros tipos de literatura permanecen en general ignorados por el mercado de las traducciones y muy particularmente la literatura de la inmigración. Nos referimos en este caso a aquella literatura escrita por un inmigrante desde el país de acogida y generalmente en la lengua de este país, que puede no ser la lengua materna del autor.

La literatura escrita en una lengua diferente a la materna desde un segundo país de destino del autor ha tenido a lo largo de las décadas muy insignes representantes que sí han contado con una amplia difusión y repercusión (Josep Conrad, Nabokov, Kundera, Rushdie), pero el mundo editorial se muestra remiso a otras voces.

Lo es a la nueva literatura de la inmigración en Italia, literatura escrita por un perfil diferente de autores, llegados desde África fundamentalmente (con el caso paradigmático del senegalés Pap Khouma), o de la Europa oriental ante las sucesivas crisis desatadas tras la caída del Muro y los diferentes conflictos.

Y, de manera paralela a todo ello, no podemos olvidar las dificultades a las que se han tenido que enfrentar las mujeres para ir abriendo camino. Pocas pero gloriosas excepciones nos encontramos en este panorama, Helga Schneider y Ornela Vorpsi son dos de ellas y su caso bien merece un estudio detenido.

\section{Helga Schneider, la pequeña huésped de Hitler}

Decir que la vida de Helga Schneider da para una novela es quedarse muy corto, porque, de hecho, ha dado para muchas novelas. Esta escritora alemana, afincada en Italia desde 1963, se ha convertido en una de las voces de referencia en todo el mundo a la hora de conocer de primera mano el horror nazi vivido por los propios alemanes.

"Berlín, otoño de 1941. Mi madre era una señora rubia que gritaba 'Sieg Heil!' cuando Adolf Hitler aparecía en sus mítines” 
“Transfer” XV: 1-2 (2020), pp. 434-450. ISSN: 1886-554

(Schneider 2005: 11). En esta frase casi se concita toda la tragedia de una niña alemana, nacida poco antes de la II Guerra Mundial, abandonada por su madre, fidelísima creyente de la fe nazi y que tras una larga serie de avatares vivió el final de la guerra en un sótano familiar, entre continuos bombardeos, hasta que entra a formar parte de un programa de una última y desesperada propaganda que le permitiría pasar a ser huésped del mismo Hitler en su búnker personal, donde conocería directamente al dictador.

Un día nos comunican que el Führer vendrá a saludarnos y Peter si ilumina de alegría. ¡Igual que si le hubiesen prometido que vería a Papa Noel en persona!

Nos preparan con puntilloso esmero para el encuentro. La primera norma es que, en presencia del Führer, no se puede alzar la voz. En el caso de que él nos pregunte algo, hay que contestar "sí, mein Führer" o "no, mein Führer". Por supuesto, el saludo nazi es obligatorio. (Schneider 2005: 84)

Tras la guerra, Helga se irá a Austria con los abuelos paternos y finalmente llegará a Italia en 1963, donde decide comenzar una nueva vida. Allí, algunos años después y siempre escribiendo en italiano como una forma psicológica de alejarse aún más de todos los dolores de la infancia, acaba por iniciar una relevante carrera literaria en la que alterna el relato autobiográfico con las obras de ficción, fundamentalmente orientadas al público infantil y juvenil.

La primera aparición de Helga Schneider se producirá en 1993, con La bambola decapitata, una novela plenamente de ficción en la que una hija hará todo lo posible por ir descartando a las numerosas pretendientes de su padre viudo.

Con haber sido una irrupción con fuerza en el panorama italiano, la importancia de esta novela que en gran medida narra el modo de vida de la clase media-alta italiana a comienzos de los 90, será fundamental porque, de forma algo inopinada, será en definitiva la ocasión para que Helga reoriente en gran medida sus pretensiones literarias. 
“Transfer” XV: 1-2 (2020), pp. 434-450. ISSN: 1886-554

Nel 1993, un editore bolognese, Pendragon, pubblicò il mio libro d'esordio: La bambola decapitata. Il giornalista Gabriele Romagnoli, della Stampa di Torino, mi telefonó facendomi alcune domande e, sentendo che ero cresciuta nel cosidetto Terzo Reich a Berlino, ed essendo figlia di una exausiliaria delle SS e guardiana ad Auschwitz-Birkenau, mi consiglió caldamente di scrivere un libro autobiografico anziché romanzi di fiction. Gli diedi ascolto, buttai giù in pochi mesi Il rogo di Berlino, che fu pubblicato da Adelphi. ${ }^{1}$

Será, por lo tanto, Il Rogo di Berlino (traducido al español como No hay cielo sobre Berlín) el estreno en el año 1995 de su andadura literaria desde esa perspectiva de retrospección autobiográfica y análisis de los muchos matices vitales de una infancia sorprendente.

Helga ha sido abandonada por su madre en un hogar del que el padre se encontraba ausente por la guerra. Ha peregrinado por varias casas, ha sido repudiada y no es de extrañar que decida poner toda la distancia posible sobre aquellos escenarios. Sin embargo, desde siempre se ha sentido escritora y cuando comienza efectivamente a dedicarse a escribir, todo ese mundo afluye de una forma torrencial e inevitable.

Yo, que nací en Polonia y viví en la Alemania nazi hasta que me repatriaron a Austria (que también era el país natal de mi padre), me había establecido ya en Italia; tenía marido y un hijo. (Schneider 2005: 9)

Es el propio recuerdo en Il rogo di Berlino a la madre, a su búsqueda para tratar de buscar una explicación a lo ocurrido, a la fascinación por la causa nazi que la llevaría a abandonar a la niña Helga a su suerte, lo que lleva a la escritora a la que es una de sus obras más conocidas: Lasciami andare, madre (en español: Déjame ir, madre).

\footnotetext{
${ }^{1}$ Entrevista a Helga Schneider publicada el 18 de mayo de 2018 en La Repubblica: $<<$ http://libri-parma.blogautore.repubblica.it/2018/05/18/scrittura-e-memorianellopera-di-helga-schneider-la-bambina-che-nel-1944-incontro-hitler-nel-suobunker/comment-page-1/>> [Fecha de consulta: 23/08/2019]
} 
“Transfer” XV: 1-2 (2020), pp. 434-450. ISSN: 1886-554

La escritora ha descubierto la triste historia de su madre como auxiliar de las SS en uno de los más negros campos de concentración. Es 1971 y realiza la primera visita a la madre que se marchó voluntariamente de casa, que renunció a criar a sus hijos por una causa que entiende superior. Por una causa que, de hecho, no ha abandonado.

No habían pasado veinte minutos cuando abrió el maldito armario para enseñarme con nostalgia aquel uniforme. “¿Por qué no te lo pruebas? Me gustaría vértelo puesto”. No me lo probé, estaba confusa y alterada. Pero lo que me dijo a continuación fue incluso más grave que el hecho de renegar de su papel de madre. "Fui condenada por el Tribunal de Núremberg a seis años de cárcel por crímenes de guerra, pero eso ya no tiene importancia. Con el nazismo yo era alguien; después, nunca he sido nada". (Schneider 2005: 10)

La madre, con su fanatismo, con su uniforme de las SS guardado en un sórdido armario de Viena décadas después del final de la Guerra. La madre que no acompañó a sus hijos en las oscuras horas desatadas por la locura genocida. La que no estuvo para intentar frenar, en lo que hubiera sido posible, la pérdida irreparable de una infancia.

Pobre hermanito: cinco años, pensé, jsolo cinco años y ya tan traicionado por la vida y por los hombres! Cinco años, Dios mío, y no sabía jugar. No sabía lo que era un vaso de leche o lo azul que podía llegar a ser el cielo. Cinco años. ¿Podrían los hombres resarcirlo de su infancia perdida? ¿Y resarcirme a mí de la mía? (Schneider 2005: 168)

Pero Helga explica en Lasciami andare, madre cómo va creciendo una sensación contradictoria sobre esa madre que necesita de alguna forma enfrentar y tratar de comprender. El dolor por el abandono, el horror por su trabajo eficaz e inmisericorde en Auschwitz: "Qué insoportable me resulta pensar que mi madre fue cómplice de todo aquello" (Schneider 2002: 18). Y al 
“Transfer” XV: 1-2 (2020), pp. 434-450. ISSN: 1886-554

mismo tiempo la sensación de que una madre, siempre es una madre: “¿Podremos salvar algo, madre?” (Schneider 2002: 20).

Será un intenso relato de apenas 24 horas en la vida de dos mujeres, madre e hija, que vuelven a verse tanto tiempo después que se convertirá, por su cruda sinceridad, por el generoso ejercicio literario de su autora, en un enorme éxito en varios países.

1941. Berlín. Barrio de Niederschönhausen. Cerca de las seis de la tarde de un frío día de otoño. Mi madre me miró con severidad. Ahora tienes que ser muy fuerte -dijo-, mamá tiene que marcharse. (Schneider 2002: 117)

Ese es el comienzo, en gran medida, de toda la historia trágica de Helga y ese es el necesario momento que hay que afrontar, una y otra vez, para que la escritora pueda seguir de alguna manera con su vida. Por ese motivo, el ejercicio de Lasciami andare, madre es tan impactante y ha abierto a su autora las puertas del reconocimiento internacional.

Solo desde esa sinceridad será posible que sintamos sin hacer preguntas las contradicciones entre la razón y el corazón: “¿Por qué he venido corriendo a Viena? ¿Quizá porque, a pesar de todo, no consigo odiar a esta madre que no es una madre?" (Schneider 2002: 131).

Entreverado en la historia familiar, en la que siempre la cuestión central será el motivo por el que Helga fue abandonada por su madre, el relato, la conversación, servirá a la escritora para poner a las claras los horrores sin matices de los campos de concentración.

Aunque el asfixiante diálogo, con episodios cada vez más crueles y sanguinarios hacia lo sucedido en Auschwitz da la sensación de pretender que de algún modo la madre tome conciencia del mal realizado, el resultado siempre es desalentador: "Bueno, hija mía - no vacila ni un segundo -, te guste o no, no me arrepiento de haber pertenecido a la Waffen SS, ¿está claro? (Schneider 2002: 149). 
“Transfer” XV: 1-2 (2020), pp. 434-450. ISSN: 1886-554

- Solo se quemaba a la gentuza - proclama con desprecio-. Alemania tenía que desembarazarse hasta del último stück, del último ejemplar de esa raza innoble.

- ¿Y tú estabas de acuerdo?

- ¿De acuerdo con qué? ¿Con la solución final? ¿Por qué crees que estaba en ese lugar, para disfrutar de unas vacaciones? - se ríe, pero sus mandíbulas no dejan de temblar.

- ¿No te apiadabas de nadie, ni siquiera de los niños? - le pregunto. No me atrevo a mirar a Eva.

- ¿Por qué? - responde enseguida. Un niño judío se trasformaría en un judío adulto. Y Alemania tenía que librarse de esa raza odiosa, ¿cuántas veces tengo que repetírtelo? (Schneider 2002: 85)

Mientras, la escritora ha ido alternando el horror de lo escuchado con una punzada extraña y dolorosa por la madre, a la que acaba incluso aceptando llamar en algún momento mutti (mamá). "Siento angustia y una ternura irracional. Es mi madre, a pesar de todo es mi madre" (Schneider 2002: 152).

Sin embargo, ni siquiera en este libro, el más íntimo de la escritora, lo personal será la única clave de lectura. Además de ese inmenso conflicto en la relación madre-hija, Helga Schneider nunca perderá de vista a la hora de escribir cuáles son sus objetivos:

I veri testimoni hanno una grande responsabilità, perché è con loro che si ricostruisce la Storia. Purtroppo quei depositari muoiono, e sono le nuove generazioni che devono assumersi la responsabilità di portare avanti il loro messaggio, per evitare che la Storia subisca un processo di revisionismo. Non dobbiamo permettere che la Storia venga falsata o seppellita. La Storia è la coscienza dei popoli. ${ }^{2}$

Por eso, Schneider continuará insistiendo en la necesidad de evitar cualquier distorsión en el mensaje histórico de lo que fue y lo que supuso el nazismo. En 2006 publica Io, piccola ospite del Führer, que será su tercer libro traducido al español (Yo, la peque-

\footnotetext{
${ }^{2}$ Cfr. Nota 1
} 
“Transfer” XV: 1-2 (2020), pp. 434-450. ISSN: 1886-554

ña invitada del Führer). Es una respuesta contundente a la posibilidad de buscar y de ofrecer a las generaciones futuras un lado humano de Adolf Hitler.

Aún sigo preguntándome si es posible mostrar el lado humano de Hitler. Si es posible, pensando en los cincuenta y cuatro millones de muertos, el sesenta por ciento de los cuales eran civiles, que la guerra de Hitler costó al mundo; en los seis millones de judíos exterminados en las cámaras de gas, en los aproximadamente dieciocho millones de personas (de las cuales murieron once millones) arrojadas a los campos de concentración en Alemania y en los territorios ocupados. (Schneider 2006: 8)

En esta novela, Schneider retoma uno de los episodios más particulares de su vida, haber residido en el búnker personal de Hitler en los instantes finales antes del hundimiento de Berlín. Será a la postre uno de los más feroces retratos de la acción de la propaganda nazi sobre el pueblo alemán. Un pueblo que o bien fanatizado o bien engañado será arrastrado a un destino trágico tras las huellas de un supuesto superhombre que no consigue, sin embargo, engañar a una niña: "nadie osa manifestar que ha visto una especie de fantasma que parece sobrevivir apenas a su propia sombra" (Schneider 2006: 133).

En Yo, la pequeña invitada del Führer, asistimos a un retrato del horror de la guerra sobre los civiles alemanes y la desesperación de las autoridades por evitar que llegara a su conocimiento la información del irremisible curso de la confrontación. Será precisamente un programa propagandístico especialmente falto de escrúpulos, el que utiliza abiertamente a los niños para tratar de ofrecer una imagen cercana y despreocupada de Hitler, el que lleve a Helga Schneider a pocos centímetros del monstruo.

En el libro, asistiremos a los mecanismos sutiles de control de las mentes, a las redes familiares, a la maquinaria nazi que tampoco renuncia a emplear a los pequeños como engranaje a través de sus Jungvolk. Así hasta el esperado momento del encuentro cara a cara con el Führer: 
“Transfer” XV: 1-2 (2020), pp. 434-450. ISSN: 1886-554

El Führer avanza hacia nosotros, pero yo no doy crédito a mis ojos. ¡Es tan distinto de como lo había imaginado! No dejo de mirarlo fijamente, con indecible estupor: el paso lento, arrastrando los pies, los hombros encorvados, el brazo izquierdo rígido como si fuese de madera y un visible temblor en la cabeza... iNo puedo creerlo! ¿Es éste el Führer de Alemania? (Schneider 2006: 128)

El rey está desnudo y una niña de pocos años, curtida en las miserias del hambre y la escasez, lo sabe. La niña que estrechará la mano blanda, caliente y sudorosa del supuesto hombre más poderoso de la tierra. "Entonces ocurre algo muy raro. El gran Führer me da pena (...) y me digo: Mein Gott, este hombre no puede hacer ya nada por Alemania" (Schneider 2006: 130). En efecto, falta muy poco para el ataque soviético que forzará la capitulación definitiva.

Una capitulación que, ya hemos conocido en Il rogo di Berlino, traerá más dolor y humillación a ese pueblo. Hambre, suicidios, desesperación y estragos del ejército vencedor ensañándose:

El ruso, que ya había empujado a Erika a un colchón, se echó encima con todo su peso. Alguno de nosotros se movió para socorrer a la madre y detener al violador, pero el que nos encañonaba con el fusil gritó algo en ruso y disparó un tiro al aire (...) lo que estaba viendo era inaudito, cruel, injusto. (Schneider 2005: 183-184)

El dolor, el corazón desgarrado de una niña cuyo relato llegará años después para subrayar el infortunio doble de aquellos civiles a los que nadie quiso.

\section{Ornela Vorpsi: la niña que leía libros a escondidas}

De Albania proceden aproximadamente medio millón de personas asentadas actualmente en Italia, siendo la segunda comunidad inmigrante introeuropea más importante, solo superada por $\mathrm{Ru}$ manía. La llegada de inmigrantes desde Albania hacia Italia ha 
“Transfer” XV: 1-2 (2020), pp. 434-450. ISSN: 1886-554

tenido fundamentalmente tres picos de intensidad: 1991 -el primer estallido, huyendo de las condiciones del comunismo tras la caída del Muro-, 1997 -tras una brutal crisis económica que sacudió al país- y 1999 -conocida como l'ondata invisibile y provocada por los conflictos en los Balcanes-.

En la primera de esas migraciones masivas, llegó a Italia Ornela Vorpsi, que permanecería en Italia durante seis años, entre Milán y Roma, para posteriormente viajar a París, donde reside actualmente y cuya nacionalidad ha adquirido. Sin embargo, desde el inicio de la carrera de esta polifacética autora, Ornela escribe preferentemente en italiano.

Al margen de su participación en otros proyectos artísticos, Vorpsi ha publicado seis novelas, de las que dos han sido traducidas al español: El país donde nadie muere (Il paese dove non si muore mai) y Puro veneno (La mano che non mordi).

El primero de ellos, está considerado como uno de los libros esenciales de la nueva generación de escritores inmigrantes y se construye precisamente como una crítica feroz hacia las condiciones de vida en la Albania de Enver Hoxha. Una Albania con una atmósfera opresiva y muy machista. Llena de odio. Vorpsi nos presenta ante las complicadas relaciones de una hija con sus padres. Él está encarcelado y ella arrastra como una auténtica maldición su belleza.

La autora desgrana en un sinfín de episodios cómo la belleza es verdaderamente un problema, porque es, al fin y al cabo, una diferencia, una distorsión en un sistema que solo quiere que todos sean igual de grises.

Mia mamma è molto bella [...] Lei passava sotto gli sguardi ammirati degli uomini e quelli invidiosi delle donne. La mostruosa invidia delle donne l'ho vista in concreto dietro di lei. Sarebbe bastato uno sguardo fatto d'amaro -di quell'acido che corrode le vene e lo stomaco- a far bruciare castelli e paesi interi. L'avrebbero spolpata o mangiata viva, l'avrebbero gettata in pasto ai cani. (Vorpsi 2005: 15) 
“Transfer” XV: 1-2 (2020), pp. 434-450. ISSN: 1886-554

Un país que lleva toda la carga de falsedad, odio e hipocresía, denunciado por la mirada de una niña que va creciendo. Del terror de vivir marcada, timbrata: "Quella pancia riempita voleva dire: chiavata nei cespugli" (Vorpsi 2005:10), a la ruptura de su mundo con motivo del divorcio de sus padres: "si cominciò a parlare sempre peggio di mio padre [...] adesso toca a lui pagare... lo sanno tutti che in prigione vende il culo". (Vorpsi 2005: 40)

Un episodio que, por otra parte, permite conocer al lector toda la capacidad de ácida ironía de Vorpsi:

Alla fine sarei diventata troia come mio padre, anzi io ero già una troia, si vedeva dal mio sguardo furbo. Poi con lui avrei aperto un negozio di puttanerie. All'entrata del negozio avremmo messo una bandiera, tipo: PUTTANERIA E CULO VENDESI. COMPAGNIA PADRE \& FIGLIA. [...] Per adesso devo aspettare. Ho dodici anni, il papà è ancora in prigione - sono progetti dell'avvenire. (Vorpsi 2005: 41)

Un estilo claro y directo que no rodea en algunas denuncias terribles. Vorpsi criticará las dificultades de, por un motivo u otro, ser diferente: "La mia uniforme militare mi sta stretta. Essendo alta, non sono nella norma che hanno stabilito per coprire i corpi delle adolescenti in Albania" (Vorpsi 2005: 78), pero subrayará problemas como la violencia de género, la vergüenza que llevaba a los abortos clandestinos o la pederastia:

La porta della casetta dei nani. Rosa, fucsia, azzurrini i cuscini, le coperte fiorite. - vieni Elona, ma vieni dentro. Vuoi dei lokum, eh? È vero che sono buoni, e poi io ne ho così tanti! Te ne posso dare centinaia! Vieni più vicino, piccola, come sei carina (...) Oh! Che bella coscetta che hai. Ti dice il tuo papà che hai proprio una bella coscetta? Mostra un po' a Babako la tua gambettina deliziosa! Dài piccola! Fai vedere a Babako com'è fatta la tua farfallina... La lavi da sola o è il papà che te la lava? (Vorpsi 2005: 29)

Una atmósfera asfixiante que llevará a la protagonista a salir definitivamente del país, rumbo a una terra promessa que poco tendrá que ver finalmente con lo ideado, pero a la que se 
“Transfer” XV: 1-2 (2020), pp. 434-450. ISSN: 1886-554

encamina con un comprensible: "al diavolo questo paese maledetto!" (Vorpsi 2005: 107). La propia autora explica esa visión de su país natal que se filtra en sus escritos:

per me è la terra dei ricordi infantili, ma anche un Paese ostile. Se sono scappata non è stato per ragioni economiche: la mia famiglia era dalla 'parte sbagliata', e il Comunismo d'impronta stalinista dell'epoca non lasciava scampo. ${ }^{3}$

Tras el importante éxito en Italia (curiosamente, el libro se publicó primero en Francia, traducido del italiano) y su llegada a un amplio número de países, en 2007 publicaba La mano che non mordi, que llegaría al año siguiente a España como Puro veneno.

De nuevo, el trasfondo autobiográfico queda patente desde el propio planteamiento, ya que es la señora Toptani, una albanesa residente en París pero con estrechos lazos con Italia, la que debe acudir a Sarajevo a cuidar a Mirsad, un amigo enfermo.

El viaje, los recuerdos, las situaciones de aquellos europeos atrapados en las convulsas coordenadas históricas de la segunda mitad del siglo XX serán una ocasión ideal para que Vorpsi muestre de manera desnuda su sentido de desarraigo, su sentimiento de perfettastraniera, ahondando en uno de los puntos esenciales de la literatura de la inmigración:

Ahora ya soy una perfecta extranjera. Cuando uno es tan extranjero, lo mira todo de manera distinta a como lo mira el que forma parte de dentro. A veces, ser condenados a mirar desde fuera provoca una gran melancolía. Es como acudir a una cena de familia y no poder participar; se interpone una gélida ventana, de cristal bien grueso, a prueba de balas, a prueba de encuentros". (Vopsi 2008: 29)

Y es que, si algo narra Puro veneno, sin duda, es lo que se ha dado en llamar la desorientación del regreso. El inmigrante que retorna a sus orígenes, aunque sea por un periodo corto, y encuen-

${ }^{3}<<$ https://cafebabel.com/it/article/ornela-vorpsi-io-lalbania-e-la-bellezza-chedisturba-5ae0050cf723b35a145dccf2/ >> [Fecha de consulta: 02/09/2019] 
“Transfer” XV: 1-2 (2020), pp. 434-450. ISSN: 1886-554

tra de repente cortadas las líneas que lo mantenían unido a sus recuerdos, a un contexto anterior que parece ya perdido, tanto exterior como interiormente: "El olor de los Balcanes despierta un pasado que duele. De nostalgia, de amor, de rencor, de desolación, de impotencia, de lejanía, de cercanía” (Vopsi 2008: 57).

Es cuando esas sensaciones comienzan a perderse, cuando da inicio ese vacío interior del desarraigo:

- Oye- dice de improviso levantando la voz, a fin de parecer más convincente-, te has vuelto verde. ¡Ten cuidado!

- ¿Verde cómo?

- Verde de emigración, pobre amiga mía. El verde de la desnutrición, propio de quien tiene las raíces al aire. Ten cuidado, porque la enfermedad de la que te estoy hablando empieza así. (Vorpsi 2008: 67)

Con ser uno de los temas cruciales en la literatura de la inmigración, no será el único que se asome a las páginas de $L a$ mano che non mordi, ya que Ornela también recogerá distintos episodios vinculados a los inevitables fallos lingüísticos, falta de manejo de los usos y costumbres o hirientes diferencias sociales entre el país de acogida y de procedencia. Es el caso, por ejemplo, de aquel matrimonio de albaneses que había llegado a Roma en busca de una vida mejor que la mujer ya no quiere y pide, arrepentida, regresar a su ciudad, Vlora. Un tira y afloja que se rompe cuando un bedel da de comer a su perro una gran lata de carne: “¿Estás viendo lo mismo que veo yo? ¿Los enormes trozos de carne que come ese animal? ¿El animal-que-come-carne?" (Vorpsi 2008: 73).

Y precisamente, si algo marca esa extraña tierra de nadie en la que se acaba por situar una perfettastraniera es la comida, quizá una de las memorias más hondas del ser humano. Por un lado, Toptani se va a sentir abrumada con esos recuerdos alimentarios: "no puedo quedarme más tiempo aquí, me hace daño, no duermo. El olor de los pimientos fritos, de la feta, de las aceitunas..." (Vorpsi 2008: 83), por el otro no dudará en llevarse de Sarajevo byrek como equipaje: 
“Transfer” XV: 1-2 (2020), pp. 434-450. ISSN: 1886-554

\begin{abstract}
Voy a comprar byrek. Quiero llevarlo a casa, a París. El alimento que fue mi sustento durante toda la infancia me sigue gustando. Mastico mientras me devoran los recuerdos. El byrek se me atraganta, algunas lágrimas corren por mis mejillas...

[...] Con este alimento pretendo contagiarles, por eso lo llevo; no es un gesto de amor, es puro egoísmo. Al ser humano le gusta trasmitir sus pasiones. Quiero escuchar de su boca hasta el infinito: ¡Pero qué maravilla! ¡Nunca hemos comido nada tan bueno! ¿Cómo has dicho que se llama? (Vorpsi 2008: 99-107)
\end{abstract}

Al fin y al cabo, como señala Ornela Vorspi, llevamos detrás nuestros pueblos como una estela de humo.

\title{
Conclusiones
}

La nueva coyuntura de movimientos poblacionales en el planeta, en el que las migraciones ya no responden a un único perfil de baja cualificación y en el que hay también una mejor respuesta de los sistemas educativos de los países de acogida, permite que se esté desarrollado de una manera notable una literatura de la inmigración, en la que las personas que llegan a un nuevo país se deciden a dejar por escrito sus experiencias y reflexiones, habitualmente con narraciones autobiográficas vinculadas a su propia condición de migrante.

En países como Italia, en gran medida esta literatura se produce originalmente en italiano y no en el idioma materno de la persona inmigrante, lo que a su vez va produciendo un enriquecimiento de estructuras y vocabulario.

Se trata de un fenómeno que ha experimentado un gran crecimiento en los últimos treinta años, ofreciendo un amplio panorama de experiencias en la mayoría de los casos situadas entre dos culturas.

En la literatura de la inmigración italiana no faltan las voces femeninas, como las de Lily-Amber Laila Wadia, Anna Belozorovitch, Enisa Bukvić, Ingrid Beatrice Coman, Elvira Dones, Anil- 
“Transfer” XV: 1-2 (2020), pp. 434-450. ISSN: 1886-554

da Ibrahimi, Irma Kurti, Guergana Radeva, Elvira Mujčić, Kenka Lenkovich, Vera Slaven o Tamara Jadrejčić y un largo etcétera.

Salvo contadas excepciones, sus obras, sin embargo, no han logrado romper las barreras nacionales y aunque muchas de ellas se han visto reconocidas con premios de prestigio en Italia, de momento son ignoradas a la hora de traducir sus trabajos para el mercado hispanohablante.

Helga Schneider y Ornela Vorpsi, con tres y dos novelas traducidas al español, respectivamente, encarnan la imagen de auténticas pioneras en este camino. Con distintos universos de referencia y contextos vitales, las dos autoras logran presentar con autenticidad y enorme claridad en ambos casos fenómenos históricos y sociales que por su valor ayudan al lector a comprender el complejo mundo heredado del siglo XX.

Otras muchas historias, otras muchas voces de mujer, otros muchos relatos apasionantes están a la espera de captar la atención de un remiso mercado editorial en el que, como hemos explicado en este artículo, la traducción al español de la literatura italiana de la inmigración escrita por mujeres puede despertar un gran interés para el lector.

\section{Referencias bibliográficas}

GNISCI, Armando. (ed.) (2006). Nuovo Planetario Italiano. Geografia e antologia della letteratura della migrazione in Italia e in Europa. Troina: Città Aperta edizioni.

MAUCERI, Maria Cristina \& NEGRO, Maria Grazia. (2009). Nuovo Immaginario Italiano. Italiani e straniera a confronto nella letteratura italiana contemporanea. Roma: Sinnos

MEHILLAJ, Orkida. (2010): "L'immigrazione albanese in Italia. Profili sociologici e politiche di controllo" [Artículo en línea], en L'altro diritto. Centro di documentazione su carcere, devianza emarginalità, Università di Firenze [Fecha de consulta: 10/08/2019] $\quad<<$ http://www.adir.unifi.it/ rivista/2010/mehillaj/index.htm $>>$ 
“Transfer” XV: 1-2 (2020), pp. 434-450. ISSN: 1886-554

SCHNEIDER, Helga. (1998). Il rogo di Berlino. Milán: Adelphi Edizioni. --. (2001). Lasciami andare, madre. Milán: Adelphi Edizioni.

---. (2002). Déjame ir, madre. Barcelona: Salamandra.

--. (2005). No hay cielo sobre Berlín. Barcelona: Salamandra.

--- (2006). Io, piccola ospite del Führer. Turín: Einaudi.

--. (2006). Yo, la pequeña invitada del Führer. Madrid: Siruela.

--- (2014). La bambola decapitata. Bolonia: Pendragon.

VORPSI, Ornela. (2006). El país donde nadie muere. Barcelona: Lumen.

---. (2006). Il paese dove non si muore mai. Turín: Einaudi.

---. (2007). La mano che non mordi. Turín: Einaudi.

---. (2008). Puro veneno. Barcelona: Lumen.

Fecha de recepción: 1.10.2019 Fecha de aceptación: 11.10.2019

\section{Resumen:}

El artículo trata de poner de manifiesto la ausencia de traducciones al español de obras pertenecientes a la literatura italiana de la inmigración. A pesar del auge que ha tenido en España la literatura del país transalpino en los últimos años, especialmente en lo que a novela negra se refiere, sólo se ha traducido una ínfima parte de literatura escrita por inmigrantes. Es el caso de autoras como Helga Schneider, de origen alemán, y Ornela Vorpsi, albanesa, que han visto traducidas algunas de sus novelas al español. El artículo pretende demostrar la importancia y necesidad de que se traduzcan más obras de este tipo a nuestra lengua cuya temática gira normalmente en torno a la historia, a la situación de los inmigrantes y a los conflictos identitarios.

Palabras clave: Escritoras; Mujeres Inmigrantes; Ornela Vorpsi; Helga Schneider; Identidades Fragmentadas. 
“Transfer” XV: 1-2 (2020), pp. 434-450. ISSN: 1886-554

\title{
BREAKING THE SECOND BOUNDARY. HELGA SCHNEIDER AND ORNELA VORPSI: PIONEERS IN THE ITALIAN LITERATURE OF IMMIGRATION TRANSLATED INTO SPANISH
}

\begin{abstract}
:
This article attempts to highlight the lack of translations into Spanish of novels belonging to the Italian literature of immigration. Despite the general interest raised in Spain by the literature from the transalpine country in recent years, particularly concerning the genre of the giallo, only a tiny part of the works written by immigrants has been translated. This is the case of some women authors such as the German Helga Schneider and the Albanian Ornela Vorpsi who have seen some of their novels translated into Spanish. The article aims to prove the importance and need of translating into our language more of these texts, that usually touch significant topics such as history, immigrants' situation and identity conflicts.
\end{abstract}

Keywords: Migrant Women; Female Writers; Ornela Vorpsi; Helga Schneider; Fragmented Identities. 